\title{
Changes in One Teacher's Proportional Reasoning Instruction after Participating in a CGI Professional Development Workshop
}

\author{
Jessica A. de la Cruz \\ Department of Education, Assumption College, United States
}

Copyright $(2016$ by authors, all rights reserved. Authors agree that this article remains permanently open access under the terms of the Creative Commons Attribution License 4.0 International License

\begin{abstract}
This study examined how one teacher used research-based knowledge of how adolescents think about proportions. Observations, interviews, document collection, and a workshop intervention were utilized. The design of the workshop was inspired by the cognitively guided instruction studies and its purpose was to explore the research findings on adolescents' thinking about proportions. An individual case study was created to describe the teacher's instruction related to proportion concepts, rationales for instructional decisions, beliefs, and changes in all of these areas after participating in the workshop intervention. The case presented here shows positive changes in the teacher's instruction and beliefs after the workshop.
\end{abstract}

Keywords Professional Development, Teacher Change, Cognitively Guided Instruction, Instructional Decisions

\section{Introduction}

Carpenter, Fennema, Peterson, Chiang, and Loef [1] and several other research studies [2-6] found participation in a content specific, cognitively guided instruction (CGI) teacher development program can (a) have a positive effect on teachers' pedagogical content knowledge and (b) lead to changes in classroom practice towards instruction guided by students' thinking. Additionally, the students of teachers who were more aware of students' thinking related to addition and subtraction, performed significantly better than control students on addition and subtraction problem solving [6] and on recalling addition and subtraction number facts [1].

Studies have revealed that teachers have weak pedagogical content knowledge related to proportional reasoning [7] and limited knowledge of their students as it relates to proportional reasoning [8]. Furthermore, students generally have a weak understanding of proportional reasoning [9-14]. There is clearly a need to improve instruction in the area of proportional reasoning and the research indicates that providing teachers with research-based knowledge of how students think about proportion concepts is a good place to start. However, there is no evidence that anyone has attempted to investigate the influence a CGI workshop focused on proportional reasoning may have on increasing teachers' awareness of their students' thinking about proportions and its influence on the teachers' instruction.

This study investigates how one teacher used new knowledge of students' thinking gained from participation in a CGI based teacher development program focused on proportional reasoning to inform her instructional decisions. The research questions that guide this investigation are as follows: (a) How did the teacher generate student thinking through her instructional decisions prior to participating in the workshop? (b) What were her instructional decisions based on prior to the workshop? (c) How did she change after participating in the workshop?

\section{Background}

The professional development workshop that is the "treatment" in this study was developed based upon two existing lines of research: research on CGI and research on how adolescents think about proportional reasoning. In this section, the methods and results of existing CGI research are summarized. Next findings of empirical studies on how adolescents think about proportional reasoning are synthesized.

\subsection{CGI Approach to Professional Development}

Carpenter, Fennema, Peterson, Chiang, and Loef [1] developed a CGI approach to both professional development and teaching in general that involves focusing on students' thinking. During their professional development sessions, 
teachers looked at problem types, strategies, misconceptions and difficulties, concept development, and the relationship between the aforementioned within a specific content domain, addition and subtraction. A CGI approach to teaching involves assessing students' thinking and using that assessment to inform decisions related to tasks, types of numbers or contexts to include, follow-up questions to ask, and how to sequence both the overall curriculum and tasks within an individual lesson. Obviously, knowledge of students' thinking is most beneficial if it is applied in the classroom. So, the ultimate goal of a CGI professional development approach is to provide teachers with the relevant knowledge and tools necessary for them to implement CGI in their own classrooms. Carpenter, Fennema, Peterson, Chiang, and Loef [1] found that the CGI teachers expected more variety in solution strategies, posed more problems, listened more to the processes students used to solve problems, spent more time on problem solving, and spent less time on number facts than the control group. Furthermore, the CGI students outperformed the control students on recalling basic facts. The results of this study indicate the use of research-based knowledge of students' thinking can help teachers to develop a deeper understanding of their students' thinking and improve instruction.

Two studies [2,5] analyzed changes in elementary school teachers' beliefs and instruction as a result of participation in a four year long CGI teacher development program. The teacher development program consisted of a series of workshops and implementation support was provided by the researchers in each teacher's classroom. Data was collected through observations, interviews, informal interactions, CGI Belief Scale scores, and student performance scores. To discuss changes in instruction, the researchers created levels of instruction. The levels of instruction show the progression from Level 1, instruction that is not cognitively guided, to Level 4, where instruction is cognitively guided. (See [5] for detailed descriptions of each level.) Through analyzing the changes in teachers' levels of instruction throughout the four years of the teacher development program, it was found that $90 \%$ of the teachers changed their instruction to become more cognitively guided. Furthermore, results of an analysis of student achievement and the teacher's instructional level revealed that changes in teachers' instructional levels had a positive influence on student achievement.

Bright, Bowman, and Vacc [15] suggest that researchers must try to understand how teachers use their new pedagogical content knowledge in planning and delivering instruction. In fact, in the domain of addition and subtraction, studies have shown that increasing pedagogical content knowledge through a CGI professional development program can influence elementary school teachers' instruction [1,2,4-6]. In addition, a teacher's participation in a CGI professional development course was found to have a positive effect on their students' achievement $[2,6]$.

\subsection{Adolescents' Proportional Reasoning Concepts}

This study draws on empirical research on the development of proportional reasoning ability (For reviews of this research see [17-19]. Researchers have afforded a detailed analysis of the development of proportional reasoning skills through analyzing the ways middle school students solve different types of proportion problems.

Similar to how 11 types of addition and subtraction word problems can be distinguished based upon the action or relationship inherent in the context and the quantity that is unknown, proportion word problems can be separated into several different types. There are two major classes of proportion problems [19]. The first, missing value problems, requires the solver to find the missing value given three others. The second type of proportion problem is called a comparison problem. Here the goal is to compare two situations which may or may not be proportionally related.

These two classes of problems can also be broken into subcategories. Many researchers have used different criteria for classifying proportion problems, such as the semantics [20], ratios [21,22], measures [23], contexts [24], or operations $[13,25,26]$ involved in the problems.

Empirical research has indicated that adolescents use many different strategies to solve proportion problems depending on the type of problem being solved. The strategies include building up [27,28], factor of change, cross multiplication, unit rate, equivalent fractions, generating pairs, equivalence class [21], and unitizing [23,29] strategies. Noelting [30] further differentiated proportional reasoning strategies according to the types of ratios that were used as within and between strategies, also known as scalar and functional strategies [31-34]. Adolescents' success and strategy selection were found to be linked to characteristics of the problem $[9,10,12,20,21,23,32,35-46]$.

\section{Methods}

The objective of this study is to describe how one teacher used new knowledge of students' thinking gained from participation in a CGI based teacher development program focused on proportional reasoning to inform her instructional decisions. The research questions that guide this investigation are as follows: (a) How did the teacher generate student thinking through her instructional decisions prior to participating in the workshop? (b) What were her instructional decisions based on prior to the workshop? (c) How did she change after participating in the workshop?

\subsection{Context and Content of the Teacher Development Program}

The teacher development program was designed to present a research-based model of adolescents' thinking related to proportions. The model starts with basic ratio and proportion concepts and how middle school students usually think about them. The basis for the model was an 
in-depth literature review and synthesis of regularities among students' solutions to different types of proportion problems.

Although they were not explicitly taught, there were several common themes or assumptions that pervaded the workshop: (a) the goal of instruction is to increase students' understanding by building on their existing knowledge; (b) teachers' instructional decisions should be based on reflections on their students' thinking and existing knowledge; (c) learning occurs through natural inquiry where students need to develop mathematical explanations and justifications and connect them to their existing body of knowledge; (d) individuals will solve problems in a variety of ways; and (e) teachers should elicit students' thinking.

Similar to other CGI studies [2], no pedagogy or curriculum was directly prescribed during the workshop. However, the mathematical content that we discussed consisted of word problems almost exclusively. Both the written and video cases used involved middle school students solving a small number of significant word problems. When the participants asked questions about how their students' thinking should be used in their teaching, rather than answering them directly, a discussion among the participants was facilitated.

The teacher development program consisted of a 15-hour workshop and on-going implementation support. Both are described in detail herein.

\subsubsection{The Workshop}

The professional development workshop took place over two 7.5-hour days. The specific purpose of the workshop was to explore research findings on adolescents' thinking about proportions and to help teachers (a) understand the development of proportional thinking; (b) understand what makes certain types of proportion problems more difficult than others for students; (c) understand students' solutions to different proportion problem types; (d) further develop their own knowledge of proportions and teaching proportions; and (e) develop research-based lessons, activities, and materials that can be used to teach proportion concepts.

The design of the workshop was primarily inspired by the CGI [1-6] and Integrating Mathematics Assessment (IMA) studies $[47,48]$. During the workshop, we discussed the research findings in the area of proportional reasoning that are related to (a) students' strategies; (b) problem types; (c) factors influencing students' success and strategy choices; (d) prerequisites to the development of proportional reasoning; and (e) developmental theories, specifically those of Piaget [49,50]; Noelting [30,51]; Milsailidou and Williams [12]; Lesh, Behr, and Post [42]; and Karplus, Pulos, and Stage [41].

Also, both written and video cases depicting real classroom teaching scenarios were used during the workshop sessions to illustrate instruction that was focused on students' thinking and to encourage the teachers to analyze the pedagogy, questioning, and roles the teacher assumed in the case. According to Sowder [52] studying cases is useful, because:

Cases provide opportunities for teachers to make judgments about what is worthwhile, to develop critical analyses of teaching and learning that is student centered, to analyze situations and weight the effectiveness if various alternatives, to exchange perspectives with peers, to reflect on their own practice, and, in so doing, to extent their pedagogical content knowledge and become empowered in ways that lead to changes in beliefs about teaching. [52 p180]

Additionally, cases provide an authentic learning experience that "...can act as a scaffold for developing theory from practice and applying theory to practice" [52 p182].

\subsubsection{Support}

Researchers have found that the process of implementing cognitively guided instruction is easier, and thus more likely to occur, when support is offered for the implementation $[16,47,53]$. When initiated by the teacher, the author served as a mentor to aid planning an instructional sequence, analyzing students work, or developing assessments. Notes were taken on the type of help that was required. These notes served as another form of data on the teacher's instructional decisions and provided insight into why a teacher was either having trouble implementing CGI or not implementing CGI at all.

This support was occasionally utilized when the teacher described her lesson ideas before she used them (perhaps looking for confirmation) or asked the author about her students' thinking after a lesson (e.g. She asked, "That was so cool. Did that work though?" referring to her students' invented strategy for finding a percent of change). Debriefing interviews and informal conversations prior to and following observations extended the workshop.

\subsection{The Participant: Julie}

Julie held bachelor's degrees in biology and education. In addition to her bachelor's programs, years later, Julie participated in, but did not complete, an interdisciplinary science master's program. Through this program, Julie received endorsements to teach physical science and mathematics in the middle school.

At the time of this study, Julie was employed as a middle school mathematics teacher. Although she had taught science for four years, she had no experience teaching mathematics. For the first half of this study, she was teaching eighth-grade mathematics: two periods of a general eighth grade mathematics class and two periods of Algebra I, for advanced eighth graders. For the second half, Julie transferred to the seventh grade to fill a vacancy. She then taught four periods of the non-advanced seventh grade mathematics course. 
The student population in the rural county where Julie taught was approximately $70 \%$ White, $20 \%$ Black, and $46 \%$ received free or reduced lunch. The student to teacher ratio at the middle school was 25 to 1 . All the mathematics teachers in the middle school participated in the two-day workshop intervention.

\subsection{Data Sources}

Prior to the workshop, past lesson plans, worksheets, and assessments which were related to ratios and proportions were collected. These lesson plans and assessments served as a basis for comparison with the teachers' instruction after participating in the workshop.

Throughout the duration of this study, any documents related to the teaching of proportion concepts were collected. The purpose of accumulating lesson plans was to serve as an indication of the teacher's decisions prior to instruction, which was compared to their actual instruction, to point out instances of decisions during instruction. In reality, the lesson plans were generally not helpful in showing the teacher's decisions during instruction due to the lack of specificity of the documents. For all of the documents obtained, the tasks used, sequencing of the lesson, entry into the lesson, and goals of the lesson were analyzed. The purpose of collecting assessments was to determine what the teacher valued as important and to what degree they used the knowledge of students' thinking to guide their assessments. In particular, in analyzing the assessments, the following questions were considered: "Are the numerical structures, problem types, and contexts varied?" and "What type of strategy is each task eliciting?"

After each of the two workshop sessions, field notes were recorded to document observations made during the session. Observations of interest were: the teachers' interpretations and reactions to the research findings presented; the questions they asked related to the research findings, mathematics content, or instruction; the teaching implications they drew from the research; and the lesson planning and assessment ideas they generated. The second session was audio recorded and transcribed to obtain direct quotes of the teachers' reactions to the research presented.

Julie was observed teaching on 16 separate instances (77 pages of typed field notes were obtained). The purpose of the classroom observations was to determine what Julie did and said during proportional reasoning instruction, how her students reacted to her instruction, and how she interacted with the students. Initially the Inside the Classroom: Teacher Observation Protocol [54] was used. But the author quickly realized the need to record comprehensive observation notes to document more specifically what was done and said while teaching. Observation notes were analyzed on several dimensions: (a) the types of tasks used, (b) the types of questions posed, (c) how the teacher generated student thinking, (d) the types of procedures taught and how, (e) the types of procedures or strategies students used during the lesson, (f) whose strategies the teacher selected to be shared with the class, $(\mathrm{g})$ the teacher's reactions to the students' strategies and thinking, (h) who was the authority on mathematics concepts in the classroom, and (i) the types of explanations teachers gave.

Interviews took place both prior to and after the workshop intervention following subsequent classroom observations. The purpose of the interviews was to determine to what extent the knowledge gained during the workshop on proportional reasoning, and their students' thinking, played a role in the teachers' instructional decisions. Therefore, the interview questions were used to provide the meaning and rationale for specific instructional decisions. The interviews consisted of two parts. The first part was semi-structured and open-ended in nature and the second part was observation-based. An interview protocol was developed and used to loosely guide the first part of the interviews. This protocol is a modified version of Inside the Classroom: Teacher Interview Protocol [54], which was created to investigate science and mathematics teaching. The interview questions on the protocol were aimed at determining: the goals of the lesson; what the teacher expected to occur; what the students did that was unexpected, how they reacted to it, and why; what the teacher would change if they were to do it again; why they taught it that way; and how they made their assessment choices. Kvale's [55] quality criteria were used to judge the value of the interview questions.

During the second, but more substantial, part of the interview, questions were developed, prior to the interview, based on classroom observations and/or the related lesson plans and assessments used. The questions were used to gain access to the teacher's rationale for their pre-instruction and during-instruction decisions. Specifically, after an initial analysis of the related observation was completed, questions were formulated to reveal the teacher's rationale for what they said or did, such as the way he or she sequenced tasks, organized the lesson, explained certain concepts, selected students to present, or taught a specific skill. Then for each of these things, the author asked, "Tell me about this. Why did you decide to do that?" [6] or "What was the benefit to the students of completing this (e.g. worksheet, task)?"

The hypothesis that teachers are constantly making instructional decisions guided the interviews. Teachers make decisions while planning prior to instruction and during-instruction. There were also two guiding methodological assumptions. One was that teachers' actions are rational and subject to explanation. Therefore, the teachers were asked to explain their teaching decisions. The other was that teachers make pedagogical decisions based on their knowledge of students' understandings. Therefore, questions were asked about specific teaching decisions that were made, such as why a task was used or why a problem was modified for certain students and not others. The protocol contained questions with two major themes: pre-instruction decisions and during-instruction decisions. Within these two topics there were broad questions about: 
what the goals of the lesson were; why the concepts were introduced in the manner they were; why tasks were chosen; why specific questions were posed; why whole group, small group, or individual instruction was chosen; how the teacher determined the sequence of the lesson; and what the teacher would do differently next time. Questions about why changes were made to the pre-instruction plan during instruction were also asked.

All of the interviews were audio recorded and transcribed to capture the participant's responses accurately.

\subsection{Data Analysis}

Miles and Huberman's [56] systematic data analysis was used to derive causal descriptions and lawful relationships among the data. There are three components to this type of data analysis: (a) data reduction, (b) data display, and (c) conclusion drawing and verifying.

\subsubsection{Data Reduction}

During the data reduction phase "the conceptual framework, the list of research questions, hypotheses, problem areas, and key variables that the researcher brings to the study all help the researcher to develop an initial list of codes prior to data collection" [56 p58]. Thus, after each observation, the author reflected on the major themes and occurrences during that class session. There were two guiding frameworks for these reflections.

The first framework was related to the mathematical content of the lesson and was derived from the literature review and the content of the professional development course. In other words, the focus was on the nature of the content explored in the session, specifically, in relation to the typical development of proportional reasoning and the common issues with proportional reasoning presented in the literature review (e.g. problem type, context, ratio type, numerical structure, strategies). For instance, after each observation the problem types and numerical structures were presented within the lesson were identified and analyzed and themes were generated through comparing problem types and numerical structures across lessons. Prior to the workshop, the utilization of "naked number" problem types (i.e. problems without context), initially coded NN, was a theme across lessons, while after the workshop the incorporation of word problems was a theme.

The second framework that guided initial memoing and coding focused on the teacher's actions and was adapted from the CGI frameworks used by Carpenter, Fennema, Peterson, Chiang, and Loef [1] and Knapp and Peterson [16]. Through this framework, the focus was on instances of elicited justifications or explanations of a student's thinking, problem solving, teacher led discussions, teacher presentations, student-teacher interactions, and questions with high cognitive demand.

Stein, Smith, Henningsen, and Silver's [57] schema defining levels of cognitive demand was used to determine the demands of the tasks and questions the teachers posed during instruction. "The cognitive demand of a task refers to the type and level of thinking that is required of students in order to successfully engage with and solve the task" (p. 11). The four levels of cognitive demand are memorization, procedures without connections, procedures with connections, and doing mathematics. (See [57] for a description of these levels.) Tasks and questions posed during observed lessons were initially coded as LOW or HIGH according to their levels of cognitive demand, with memorization and procedures without connections considered LOW and procedures with connections and doing mathematics deemed HIGH.

Similarly, after each interview, a brief reflection on what was learned from the interview in relation to the guiding frameworks was written. In particular, these reflections examined the teacher's reasons for his or her pre- and during-instruction decisions. After the initial memoing and coding, pattern codes were developed to identify emerging themes or explanations. For example, the following pattern codes evolved: (a) TEST: The looming end of the year SOL exam seems to be an important factor influencing the teachers' instructional decisions and (b) PROB: Before the workshop, the teacher asked her students to solve naked number problems, but afterwards she asked her students to solve word problems, with reasons for this difference coded as BLF: changes in beliefs and KNOW: changes in knowledge.

\subsubsection{Data Display}

Next, the data were reorganized and reduced to become more manageable by creating visual displays ranging in form from structured summaries of observations and interviews, vignettes illustrating communication patterns between the teacher and their students, and network diagrams illustrating the relationships between the factors influencing change were generated to help reveal the meaning of the data.

\subsubsection{Conclusion Drawing and Verifying}

Conclusions were drawn in accordance with the processes described by Miles and Huberman [56]. In particular, to draw conclusions about the meaning of the data: (a) patterns in the data were noted. Specifically, patterns were clustered and examined with respect to the scheme for characterizing teacher development by levels of CGI, depicted in Table 1 [4]. (b) The plausibility or the reasonableness of preliminary conclusions was examined by considering the entire data set and triangulating across methods. And (c) instances were compared and contrasted across multiple observations, between observation data and lesson documents, and between expressed rationales during interviews and teachers' observed actions. Furthermore, conclusions were verified by searching for its representativeness, as well as searching for disconfirming evidence both across data collection methods and within methods. 
Table 1. Franke and Colleague's [4] Scheme for Characterizing Teacher Development in Terms of their Use of Students' Thinking.

\begin{tabular}{|c|c|}
\hline Levels & Characteristics \\
\hline Level 1 & $\begin{array}{l}\text { The teacher does not: } \\
\text { - believe students can develop problem solving strategies on their own } \\
\text { - } \quad \text { use problem solving in the classroom } \\
\text { - } \quad \text { ask students about their thinking } \\
\text { - } \quad \text { use student thinking to make instructional decisions }\end{array}$ \\
\hline Level 2 & $\begin{array}{l}\text { The teacher: } \\
\text { - believes students can solve some problems on their own } \\
\text { - believes students have mathematical knowledge that they bring to the classroom } \\
\text { - } \quad \text { recognizes that there are a variety of problem types and solutions } \\
\text { - } \quad \text { shows students how to solve problems } \\
\text { - does not use student thinking to make instructional decisions }\end{array}$ \\
\hline Level 3 & $\begin{array}{l}\text { The teacher: } \\
\text { - allows students to solve problems in their own way } \\
\text { - } \quad \text { believes that students own solution methods make more sense to them } \\
\text { - } \quad \text { has a variety of problems } \\
\end{array}$ \\
\hline Level 4A & $\begin{array}{l}\text { The teacher: } \\
\text { - believes that students' thinking should drive instructional decisions } \\
\text { - } \quad \text { problem solving is a major aspect of the classroom activity } \\
\text { - } \quad \text { encourages students to share their thinking } \\
\text { - } \quad \text { describes in detail, individual student's thinking } \\
\text { - makes instructional decisions based on students' thinking }\end{array}$ \\
\hline Level 4B & $\begin{array}{l}\text { The teacher: } \\
\text { - knows how understanding develops from connecting new knowledge with prior knowledge } \\
\text { - } \quad \text { creates opportunities to build on students' mathematical thinking } \\
\text { - describes in detail, individual students' thinking } \\
\text { - } \quad \text { recognizes relationship between problems, strategies, and development } \\
\text { - makes instructional decisions based on students' thinking }\end{array}$ \\
\hline
\end{tabular}

\subsection{Establishing Validity}

First, validity was addressed by testing conclusions about patterns. To do so, the data were searched for negative evidence, the meaning of outliers was examined, and instances were compared and contrasted. Explanations of the conclusions were also tested through the process of ruling out spurious relations, investigating rival explanations, or member checking. Second, validity was addressed by considering researcher effects. Inevitably, the author's presence in the classroom effected the teacher's and the students' actions. The teacher may have acted in the way that she believed the author wanted her to act. This potential bias in the data was carefully considered in the data analysis process. Through triangulating the data across methods, interviews, observations, documents, and surveys, as well as instances, any researcher effects should have become apparent. Those apparent effects were weighed against the evidence. To further ensure internal and external validity, member-checking and peer debriefers were used to check the author's interpretations of the data and a comprehensive audit trail was left.

\subsection{Reporting the Findings}

A case study approach was used because it allowed the author to describe in detail (a) what teachers do in the classroom, (b) the teacher's rationales for her instructional decisions, and (c) the teacher's planning for the teaching of proportion concepts and their instruction on proportion concepts before and after gaining access to research-based models of the ways in which students think about such concepts.

\section{Julie's Case}

This case study is made up of three sections. The first section describes a lesson Julie taught which introduced ratios and rates, her teaching style, and her instructional decisions before participating in the CGI workshop on proportional reasoning. The second section documents a lesson Julie taught which introduced ratios, her teaching style, and her instructional decisions after participating in the workshop. The final section of this case presents an analysis of the changes in Julie's teaching style and instructional decisions from before the workshop to after.

\subsection{Before the Workshop}

\subsubsection{A Lesson on Ratios}

Julie began her lesson introducing ratios and rates by asking her students to complete warm up problems from their textbook on reducing fractions. After the students completed the warm up problems individually, they put their answers on the board. Then Julie briefly introduced ratios as another name for fractions where things are compared. She instructed the class to "Fill in the squares 
[on the note-taking guide] with a partner and your book."

When finished, the students all returned to their seats and Julie filled in the blanks on an overhead copy of the note-taking guide. Then, individually, the students completed the last section, titled "Check for Understanding." For homework, Julie assigned the "Re-Teach" section in their textbook.

During an interview, Julie explained why she likes using the exercises from the re-teach section of her text in the following excerpt: "The re-teach usually works a problem out for them and gives them ten easy problems [exercises] to do in class to see if they are doing them right. And then I assigned for homework the left hand side of the page which always includes at least two word problems." The note-taking guide, that Julie asked her students to complete using their textbooks, see Figure 1, mimicked almost identically the textbook section on ratios and rates, see Figure 2. Julie's students merely had to copy what was in the book onto their note-taking guide. In addition to being closely related to the textbook, the note-taking guide also prescribed what action the student should take to fill in each box, as shown in Figure 3.

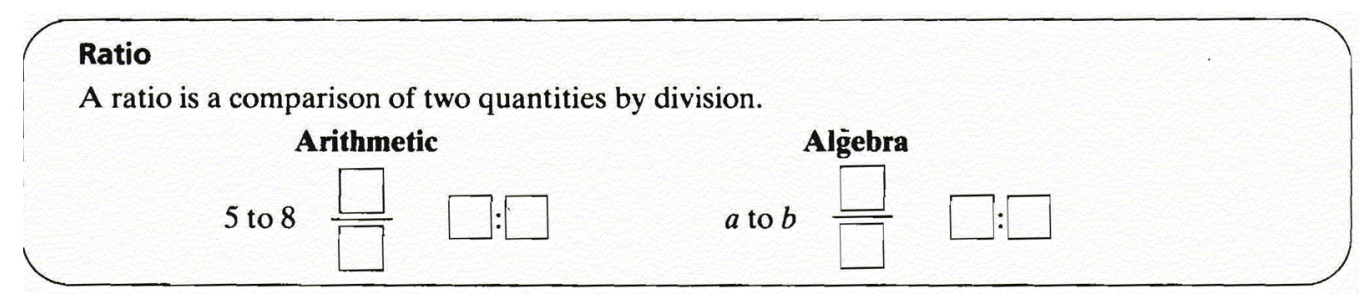

Figure 1. Excerpt from the note-taking quide.

\section{Key Concepts: Ratio}

A ratio is a comparison of two quantities by division.

\section{Arithmetic}

5 to $8 \frac{5}{8} \quad 5: 8$

\section{Algebraic}

a to $b \quad \frac{a}{b}$ a:b where $b \neq 0$

Ratios compare a part to a part, a part to the whole, or the whole to a part.

Figure 2. Depiction of the textbook.

Julie believed that this method of filling in the note-taking guide would generate more thinking from her students than the alternative of filling in the blanks on an overhead:

The rationale was a think-pair-share. So they were supposed to do the think part by themselves and they could use their books. Prior to this all they would do is sit there and watch me fill in the little squares and so they were not thinking it, they were not trying to figure out what is it trying to say to me. So the think-pair-share part was to go to their book, to think it through because the book has it written out.

In general, Julie's expectations for her students' ability to think individually were dramatically low. This is evidenced by her response to two students who were off task, "It tells you right here exactly what to do [pointing to the book]. It tells you where to put the numbers."

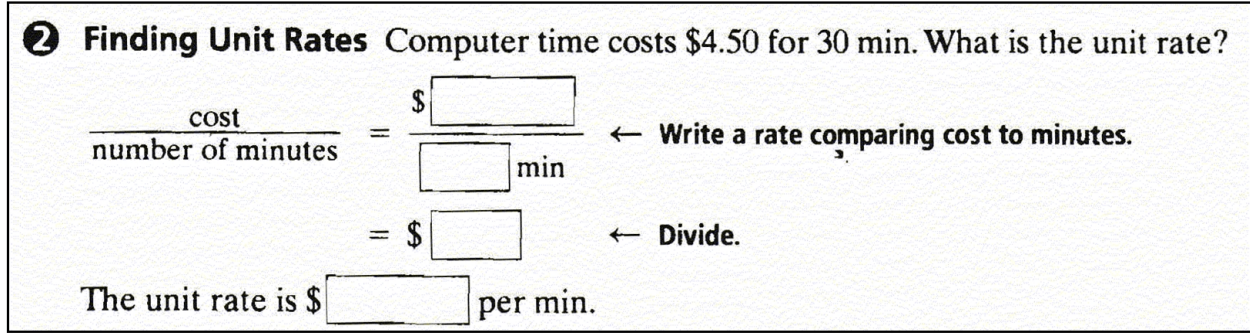

Figure 3. Exercise from the note taking-guide 


\subsubsection{Teaching Style}

Prior to participating in the CGI professional development workshop on proportional reasoning, Julie's lessons followed a prescribed format: anticipatory set, direct instruction, and independent practice. The anticipatory set generally took the form of warm-up exercises from the textbook. Then direct instruction involved completing a note-taking guide, either as a class or in pairs using the textbook. And for independent practice, Julie would have her students complete the "Re-teach" section in their workbooks which involved a collection of exercises similar to the ones students completed earlier in class.

Julie was observed using this lesson format to introduce ratios and rates. When asked about how she anticipated teaching proportions, again Julie described the same format: "Oh, I can tell you exactly how I will teach it. I will use the book and workbook to introduce proportions. The students will do warm up problems from the book, fill in a graphic organizer or notes but a modified version of the book one to make it less busy and followed by more book problems."

\subsubsection{Sequencing and Planning}

From both observation and speaking with Julie, it was clear that the textbook played a major role in informing her instructional decisions. When asked about her use of the textbook, she replied, "It is the major source right now that I am using." Julie's reliance on the textbook seemed to stem from her lack of confidence as a mathematics teacher, resulting from her unfamiliarity with the content and lack of experience teaching it. She felt that she could count on the textbook to have appropriately sequenced materials and to cover the mathematics that her students needed to know: "Next year I will probably use it [the textbook] but not be married to it like I am this year. You know, you do I guess everybody does, their first year you have no idea so they use something that they can count on. And then as you get used to it and you get used to the students and how they react to the information, then you start playing with it." Moreover, on why she used the textbook and the note-taking guide to teach ratios and rates, Julie said, "It came with the book so it should go with the chapter that we are studying. And I pretty much, because this is the first time that I have taught this class, that I have taught a math class, I want to feel that they are getting the information that they are supposed to be."

The pacing guide also played a major role in Julie's instructional planning. She would look to it to determine the broad sequencing of the mathematics topics and to obtain the lesson objectives. Without looking at the pacing guide, Julie could not say what she would be teaching after ratios and rates. Her response to, "What else will you be teaching this week?" was "I have not sat down and looked at the pacing guide. I have not looked at that to see. But I will go with the pacing guide, so whatever is right after rates. It will probably be proportions." After consulting with the pacing guide, she would look to the textbook to outline how to teach the specified topics.

Julie also used the textbook as an authority on the mathematics content. She said, "At least they [the students] could see that it is in the book." While teaching the lesson on ratios and rates, Julie repeatedly referred to what the textbook said or wanted the students to do, rather than what she wanted the students to do. During this lesson, she said, "Now they [the textbook authors] say you can check. What they wanted you to do was to go back and multiply to check."

Julie's focus on correct answers also became apparent when I asked her about whether or not students shared their strategies in class. She responded,

Well, then what happens is at the end they go through and then they show how they did it. You call on a group and say alright, you've got it right. Or the teacher gets to go around and if they have done it a really unique way, they have gotten the answer in a unique way, then you have that group go and put it up on the board and show how they did it. And then you can sit there and go, did anybody work it this way, is it plausible, how would you do it differently? And then somebody would put the normal way up on the board.

One can infer from Julie's choice of words and tone of voice when she referred to the "normal way," that she wanted to convince her students who solved the problem in a unique way that they should solve it in the standard way.

Julie's procedural and one-way emphasis in her teaching is further illustrated when she said, "If I could sit down and come up with some problems. The big thing about it is I need to come up with fail proof information. You know, you start here and you end up here." She would like class to be predictable, where students all use the same methods for solving problems.

Julie's teaching prior to participating in the workshop on proportional reasoning did not encourage students to discover their own strategies for solving problems. Instead, when students solved problems in her class, they were not expected to solve problems on their own but to use procedures outlined in the book or in a step-by-step fashion on their note-taking guide.

\subsection{After the Workshop}

\subsubsection{A Lesson on Ratios}

Similar to when she introduced ratios and rates in the eighth grade, Julie used equivalent fraction problems as the warm-up problems to help her students recognize the factor of change strategy and relate fractions to ratios when beginning a lesson on ratios after the workshop (note that Julie was now teaching in the seventh grade). She used six equivalent fraction problems, like (1), where the

$$
\frac{2}{3}=\frac{?}{24}
$$

factors of change were all "nice" whole number values 
between two and nine, but were increasingly difficult to recognize. Julie called on individual students to present each of the warm-up problems and all of them used a factor of change strategy where a factor of change is found either across the ratios (numerator to numerator and denominator to denominator) or within the ratios (numerator to denominator). Julie asked for "any different ways," but no other strategies were shared with the class.

Next, Julie placed a picture on the overhead showing six cupcakes and two boxes. The directions said, "Look at the picture and write the ratio it suggests." The following illustrates the discussion that occurred next:

Julie: Ok what are the two objects we are comparing?

S1: Cupcakes and boxes

Julie: How can we compare them?

S2: Six dot-dot two [6:2]

Julie: Hm. Oh, colon. These are just numbers right? Are we just comparing numbers? What are we comparing?

S3: Those two [objects].

Julie: So the six is what?

S3: Cupcakes.

[Julie wrote 6:2 with cupcakes written below the 6 and boxes written below the 2 .]

Julie: S4 you said you did it differently.

S4: I said you could put three cupcakes in each box.

Julie: This is six cupcakes, two boxes what are you saying?

S4: Three cupcakes, one box

[Julie wrote $3: 1$.

Julie: Is there a pattern here, what do you see? S4 can you give me another ratio?

[Julie wrote: Cakes: Boxes, 3:1, 6:2

S5: Divided by three.

Julie: Divided what by three? If I have three boxes, how many cupcakes would I have?

S5: Nine.

Julie: Do you have another one?

S2: 12 to 4

Notice that Julie's students discovered the relationship between cupcakes and boxes and were able to maintain that relationship and write equivalent ratios to the one shown. Next, Julie placed another picture on the overhead, this time of twelve lollypops and four people and instructed the class to "write the ratio this picture suggests and try to make a chart of equivalent ratios." The students did not appear to have any difficulty creating a chart of equivalent ratios $(12: 4,6: 2,3: 1)$.

Consequently, Julie put a picture of a candy jar containing thirteen jolly ranchers (JR) and five jawbreakers (JB) and asked the class to again write the ratio depicted in the picture and write as many equivalent ratios to the first ratio as they could. It is important to notice that while the directions were similar to the two previous tasks, the numbers involved in this task were quite different, in fact they were prime numbers. Thus, the techniques that the students used previously to find equivalent ratios would not work as smoothly and Julie knew this from what we discussed in the workshop. We had considered this exact problem in the context of a written case [58]. Previously, Julie's students either divided both quantities in the ratio by two or they found the unit rate and used it to find other ratios. For this example, if the students used either of these strategies they would get non-integer values for at least one of the quantities of JR or JB. Just as research suggests that students are likely to use an additive strategy when the ratios are non-integer values, a student presented an additive strategy for finding equivalent ratios on this task. $\mathrm{He}$ incorrectly wrote the equivalent ratios as 5:13, 1:8, and 8:15 and explained, "I added seven [to get from eight to fifteen]. That is what I did to get from one to eight too." Julie then asked the class, "Do we get the same ratio when we add?" and "How can we determine if we have the same ratio?" As a class, they decided that they could divide thirteen by five and eight by one to determine if they get the same result. Next, they discussed how they could create equivalent ratios by multiplying the number of JR and the number of JB by the same value.

Subsequently, Julie asked her students to complete the "re-teach" section in their workbook related to ratios. Several of the questions required writing ratios in three ways while others required writing equivalent ratios. In an interview, Julie described her rationale for having her students complete the re-teach portion of their workbook: "They got the ratios down. Now on the state test they will ask them to write the ratios in a different form, you know is this correct. So they will be able to recognize that now. And they did have to factor. So they are practicing that they need to multiply and divide but not to add or subtract." In other words, Julie wanted her students to practice writing ratios in different ways and finding equivalent ratios so that they would be prepared for state-mandated testing.

\subsubsection{Teaching Style}

After participating in the workshop, Julie generally began her lessons with either warm-up problems. Contrary to before the workshop, the numbers involved in these problems were usually chosen for specific reasons and Julie tried to sequence the problems in order of increasing difficulty. The knowledge needed to answer the problems was typically prior knowledge that related to the new concepts to be learned in that lesson, with the exception of the percent change lesson where Julie used similar figure warm-up problems.

In each classroom observations after the workshop, Julie allowed students to discover and present their own strategies for solving problems. Not once did Julie use a note-taking guide, teach a procedure before allowing students to solve problems in their own ways, or encourage her students to read their textbook because it tells you "exactly what to do." Not only did she allow and encourage her students to invent their own methods for solving problems, Julie asked her students to present their methods 
on the board and frequently asked for different ways to approach the same problem. It became apparent that Julie was taking this approach even when I was not observing her because her students were volunteering to put their work on the board, explaining what they did without being asked, and announcing that they took a different approach to the problem without Julie asking for them. Therefore, sharing their thinking was becoming more of the norm in Julie's classroom.

At times Julie's lack of content knowledge, and pedagogical content knowledge, led to her taking a procedural or formulaic approach to solving problems. This occurred when the students were confused about writing percent proportions and Julie was unable to explain it in terms of the part and the whole in a way that the students understood. She actually explained it incorrectly at first. Not knowing what to do, Julie taught the is-over-of rule for percent proportions. Similarly, when Julie and her students were confused about whether the change goes over the original or the larger of the two values [original, new] when writing a percent proportion to find the percent of change, Julie asked the class to come up with a formula. One student shared the commonly known formula for percent of change: change over original equals percent of change over one hundred. Perhaps Julie was not anticipating this formula, because she asked the class to test this student's "theory" by comparing it to one of their other strategies. Moreover, after class, Julie walked over to me and said, "That was so cool. Did that [formula] work though? Because there was a question about that." The only other time that Julie's teaching was procedural, in nature, was when she taught CM.

After the workshop, Julie focused her lessons around problem solving but, initially the problems were not word problems but naked number problems, where in later observations, Julie focused more on word problems than the latter. Immediately after the workshop, she said, "I would like to be able to put up a word problem and have them go through it and work it. But, they need a lot more structure. And they immediately see a word problem and they freak." However, after attempting to begin class with word problems, Julie realized that she could start with a word problem and have her students discover ways to solve it. After she had tried this approach several times, she saw that it was working. She voiced,

They are to a point now that they are all willing to share even if they are not necessarily correct, we saw that today with V. ... It has been tough, but it is so nice to see the progress. One student was with his parents at the parent-teacher conference and he said, 'With Mrs. J and before with Julie he wasn't getting it, but now he is starting to get it.' The difference was not in Mrs. $J$ and me, but in the presentation of the material.

Thus, a few weeks after the workshop, Julie believed that her students were doing better as a result of her new teaching style: focusing on word problems and encouraging students to develop their own methods for solving them.

\subsubsection{Sequencing and Planning}

Post workshop, Julie planned her lessons with a progression of problems and relied much less on the textbook when planning. She described her lesson sequence, "Start with an easy word problem that would be the bones of it and then the next problem would be a twist in it. Like we did, I give them a twist in it and see if they can figure it out from there." On another occasion she said in her lesson planning, "I always do try to make it simple and put a twist in each one so they can see something different."

When she was teaching in the eighth grade, shortly after participating in the workshop, Julie relied heavily on the textbook to plan her lessons and pose problems according to students' development of mathematical ideas. She did not have confidence in her own ability to understand the natural development of concepts, but believed that the textbook writers knew better than she did how to sequence a lesson. So the progressions Julie used were typically very similar to that of the examples in the textbook. Additionally, Julie did not pay much attention to how the numerical structure or contexts involved in the problems she selected influenced their difficulty; instead she considered the strategies they were likely to elicit.

Conversely, later, when she was teaching in the seventh grade, Julie relied much less on the textbook to sequence her lessons. Instead she used problems and ideas directly from the workshop, such as the cupcakes and boxes; lollypops and people; jolly ranchers (JR) and jawbreakers (JB); ratio tables; choosing numerical structures to influence strategy choices; and the rubber band stretcher activity [58]. When she was planning her lessons on ratios and proportions in the seventh grade, Julie said, "I took the [workshop] notes and was reading through the ratio part and read her article [the case] again." When the problems Julie used did not come from the workshop, Julie found them in a test bank. She seemed to have a new focus or reliance on the test problems because of the pressure she felt for the students to do well on the state exam at the end of the year. To this effect, Julie commented, "But basically I pretty much take it from the Flanagan [test bank] because those are the questions that model the state tests. So if I have an administrator come in here and say, 'Well, where did you get your questions?' I can say, 'There is the state test and those are the questions that you wanted me to use."'

\subsection{Changes from Before to After the Workshop}

\subsubsection{Teaching Style}

Before participating in the CGI professional development workshop, Julie's lessons followed a prescribed format: warm-up, direct instruction, and independent practice. Three months after participating in the workshop, Julie told 
me that she still used the same format to design her lessons. However, the difference was in what she used for each of the components. For instance, before the workshop, Julie used the textbook and a note-taking guide as the directed instruction. Then for the independent practice, she had her students complete the "Check Skills for Understanding" portion of the note-taking guide, which had exercises similar to the ones completed in the first portion of the guide, with the help of step-by-step instructions or procedures.

After participating in the workshop, the lines between the components were somewhat blurred. In particular, when Julie introduced proportions in the eighth grade, she began with warm-up exercises and then asked her students to solve word problems and share their strategies at the board. There was no direct instruction portion of the lesson according to her definition: "Direct instruction is when I give it to them. We would have gone step-by-step so they can see how to do it." Similarly, in the seventh grade, when Julie introduced ratios she began with warm-up exercises and then she asked her students to write ratios and equivalent ratios based on visuals and then work in pairs to solve problems. Again, there were no step-by-step instructions given on how to form ratios or equivalent ratios. Not only did Julie abandon the "direct instruction" portion of her lessons on proportions after the workshop, but also on lessons related to ratios, percents, similar figures, percent of change, and probability.

After the workshop, Julie still believed that some drill and practice is necessary to solidify procedures. The amount of thinking and reasoning Julie required, and expected, from her students changed drastically from before and after she participated in the workshop. Prior to the workshop, Julie described the students following prescribed steps and copying definitions from the textbook as "thinking it through." After the workshop, Julie required more and more thinking and reasoning out of her students during class. Immediately post workshop, she asked the class to solve proportion word problems without talking about how to do so. Her students were asked to put their solution strategies on the board and were required to "explain what you did."

Across all proportion related lessons after the workshop, Julie consistently used problems (tasks with no obvious solution method), although at times not word problems, and involved her students in sharing their strategies at the board. Her students were always required to explain what they did verbally; however, with time, Julie expected more reasoning out of her students. Immediately after the workshop, Julie would say, "You have to tell us what you did," and the student would describe the process they followed such as, "times three by five and times seven by five to get fifteen over thirty-five," instead of describing why they multiplied the numerator and denominator by five, how they knew to multiply by five, or why they set up their initial ratio as three over five.

Over the span of three months, Julie progressed to asking questions with higher-levels of cognitive demand. In other words, she asked more "why" questions to get at students' reasoning behind the processes they performed. For example, the following dialog from a lesson on ratios and proportions, in January, illustrates Julie's higher-level questioning style:

Julie: Ok, explain your thought process.

S: From the last thing [problem, we have] 100 over 260. The total [number of] candies is 720 and you just double both [100 and 260] it will equal 720 .

Julie: How did you know to double it?

S: Since 360 was the total of the last one, you double that to get 720 .

In addition to expecting more reasoning out of her students after participating in the workshop, Julie also changed from a procedural or one-way approach to solving problems to allowing students to use several different ways. Julie was looking for the "normal" way before the workshop. But afterwards, she started looking for different ways and collecting all of the different approaches the students took for one problem on the board. When selecting students to present their solutions on the board, after the workshop, Julie said,

The first one I want correct, so I am looking for a correctness. And then the other one I am looking for something different. I am looking for them to flip it around or do something different with it. So the first one is what I see everybody is doing and it is correct. And the other ones I am trying to find something different so they can see that it is done in different ways. I like that.

Thus, after the workshop, Julie was not only more aware of different ways to approach proportion problems but also wanted her students to know that "there are different ways to look at it. So if you are looking at a different way, you may be correct. See how Sam's strategy is different but valid."

I observed Julie and her students following exact procedures and formulas before the workshop, but after the workshop Julie usually avoided formulas and procedures. Her aforementioned teaching style of using problems and allowing individual students to discover their own methods for solving them was quite opposite from teaching step-by-step procedures. However, there were three instances where Julie was observed reverting to a procedural or formulaic approach. First, after attempts to explain percent proportions through thinking about parts and wholes failed, Julie relied on the is-over-of formula.

Similarly, when Julie was confused about writing percent of change proportions, she asked her class to "come up with a formula" and then "test their theory." Alternatively, before the workshop, Julie probably would have told the class the formula and then they would have practiced it. Therefore, even though Julie asked the students to create a formula, she progressed because she placed the responsibility and authority on the students rather than 
herself.

Finally, the one area where Julie repeatedly resorted to a procedural approach was in describing CM. A few students were able to recall "the butterfly method," more commonly known as CM, from the sixth grade and would use it as a strategy for solving proportion problems. In one class I observed, a student said, "My teacher taught me to circle it and multiply," referring to CM. The first time this occurred, in between the workshop sessions, Julie immediately demonstrated the steps of CM to the rest of the class. As a result, the students went from being involved and sharing their strategies to acting disinterested and disruptive. Julie admittedly was "more comfortable" with CM than the other strategies, and that comfort factor ultimately led her to push $\mathrm{CM}$ early on in the lesson, saying "This $[\mathrm{CM}]$ is the more correct one [strategy]" referring to two students' strategies for solving a proportion word problem: $\mathrm{CM}$ and factor of change.

A few months later (after the workshop), in a different class, when a student shared a CM strategy for the first time, and another student admitted that they did not understand it, Julie said, "That is ok, if you are using the factor method, that is fine." However, two days later, Julie demonstrated the steps of CM after another student shared it as their strategy. When I asked Julie about her rationale for demonstrating $\mathrm{CM}$ during this class, but not two days before, she responded, "We were ready to go to CM, we were doing really well with factoring." Julie seemed to believe that $\mathrm{CM}$ was the ultimate goal in developing proportional reasoning. She even referred to the CM strategy as the "proportional one [strategy]." She was also affected by the fact that she believed that students need to know CM to do well on their SOL exam. During one interview, Julie pointed out to me that the pacing guide [curriculum framework] has $\mathrm{CM}$ on it, so "CM has to be in here, we have got to get there." In fact, the curriculum framework describes $\mathrm{CM}$ as a method for solving proportions under the "teacher notes" section.

\subsubsection{Sequencing and Planning}

During the first workshop session, we discussed how teachers can pose problems in a progression so that students can move higher in the development of proportional reasoning strategies and understanding proportionality. Moreover, we read and analyzed a case describing a lesson on ratios and proportions that progressed from students recognizing different ratios, part-part and part-whole, to then projecting both types onto another situation maintaining the same ratio. We discussed the purpose of each problem and why they were used in sequence. Then the participants, by grade-level, created a lesson plan that was progressive in that it would move the students along in their development of proportion strategies.

This type of planning seemed to really resonate with Julie. At the end of the first session, Julie said, "The first thing I am going to do is use that lesson. I want to see how it works." In fact, the next day, Julie used a lesson similar to the one she and her colleagues developed during the workshop. She said, "I would have done that lesson but I didn't have it, so I recreated it. I modeled it on that." That day Julie sequenced her lesson to encourage students to move along in the development of proportional reasoning strategies, from using a factor of change strategy to using $\mathrm{CM}$. The problems she used progressed from warm-up problems with easily recognizable factors of change, to encourage that strategy, to three word problems with no integer factors of change, to encourage the CM strategy. She said she "wanted to lead them into discovering CM or needing the CM algorithm." And she did so by choosing "the numbers in the problems specifically because I knew that in the warm up they would be able to multiply by two for all the fractions or equivalent ratios, so I knew that strategy would come out of it. But with the word problems, I wanted to use more difficult numbers and especially the last one, 7800, I wanted to make sure that it was not easy to find a multiple [factor]." This already was a drastic change in Julie's teaching style. Before the workshop, Julie did not create her own lessons per se; instead, she relied on the lesson materials that were supplied with the textbook. Thus, before the workshop, she did not choose specific numbers to encourage a particular strategy or to create a progression of problems. Also, previously, she did not allow her students to discover their own strategies.

It was not until the second workshop session that we discussed sequencing problems within a lesson according to their difficulty, by evaluating the numerical structure or context of the problem in addition to the strategy likely to be elicited. Before that session, Julie did not consider the difficulty of the problems she was using in her lessons according to their contexts or their numerical structure. But, between sessions, she ordered her problems according to the strategies that she thought students were likely to use to solve them, which she also did not do before the workshop. In her lesson introducing proportions, between workshop session one and two, all three word problems she used would be considered to be at the most difficult level according to their numerical structure. Additionally, in the second session, we talked about how using contexts that are familiar to the students and measures that are well-associated can be facilitating factors for students. Before that session, Julie did not use familiar contexts or well-associated measures when creating or selecting the problems to include in her lessons.

Similar to her lesson between the workshop sessions, after Julie participated in both workshop sessions, her lessons followed a "progression." While she was teaching in the eighth grade, the source of Julie's progressions was the textbook. Specifically, she described planning her lesson on percents as, "I looked at their book and I saw how they progressed: example 1 , example 2 , example 3 , and example 4. ... So I thought, ok that is a progression that I can do. So that is what I did." Her problem sequences from lessons on similar figures and percent of change, in the eighth grade, also closely mimic the related sections of the 
textbook, with all of them following the same general progression and some of them using exactly the same phrasing.

Conversely, the major source for Julie's problem sequences when she taught in the seventh grade, which was later in the year, was not the textbook for her lessons on ratios, proportions, and similar figures. Instead, Julie's ideas were influenced by the workshop materials and a new source, the Test Bank. Before planning how to introduce ratios and proportions in the seventh grade, Julie said "I am getting ready to go back into proportions. I am getting ready to pull out my old notes and yours [from the workshop]."

In addition to the workshop materials, textbook, and Test Bank, the pacing guide also had a strong influence on Julie's planning decisions, both before and after the workshop. She used it to determine the overall sequence of the topics and how many lessons she should use to cover each topic. But as I mentioned earlier, after the workshop, Julie was not completely dependent on the textbook or pacing guide for her progressions within each lesson

\subsubsection{Knowledge and Confidence}

Although knowledge was not directly measured, it was clear through Julie's comments that she increased both her content and pedagogical content knowledge through participating in the workshop. As a result of her increased knowledge, Julie's confidence in teaching mathematics also increased. Not only did she learn about correct and incorrect proportion strategies that she had not previously considered, but she also became more comfortable with deciphering students' strategies. After the workshop, when we were discussing one student's "surprising" strategy for finding the percent of change and how she was able to make sense of it on the fly, she said, "Yeah, that is growth. Before I would have been flustered, but now you've made me more comfortable with thinking it through." And actually, the first time when a student used a strategy that Julie did not recognize, which was between the two workshop sessions, she panicked, pointed to $\mathrm{CM}$, and said, "This is more correct." In addition, Julie spoke about how she did not know to look for a factor of change before the workshop, she said she would have always used CM: "I didn't know to look for factoring; you taught us that in the class." She also admitted during the second workshop session that she always wrote ratios as within-state ratios, and would not have thought to use the between-state ratios, which she used after the workshop.

Julie also gained pedagogical content knowledge through participating in the professional development workshop. She told me that she learned how to use "discovery" in mathematics and how to classify problems.

You showed me how to do discovery. I knew to do it, but I didn't know how to do it. So you gave me the information to be able to do it [starts crying]... Plus, you showed like we had gone over classifying problems, what are the easy [easier ones]. Because I would have done naked numbers, because they are stripped down, they are easy. So you taught me to look at that stuff.

By discovery, she is talking about using problems and allowing students to generate their own strategies for solving them, as opposed to teaching strategies or procedures.

\subsubsection{CGI Schema}

After participating in the workshop, Julie progressed from Level 1 to Level 3 according to the CGI scale [4], seen in Table 1. In fact, Julie actually possessed some of the characteristics of a teacher at Level 4A after the workshop. Table 2 presents characteristics of Julie's teaching actions and beliefs, determined primarily from observation and interview data, which can be compared to characteristics of teachers at Level 1, 3, and 4A.

\section{Conclusions}

Like Carpenter, Fennema, Peterson, Chiang, and Loef [1], I developed a framework of students' thinking about proportion problems (students' strategies, problem types, and the relationships between them) and used that framework as the core of a professional development workshop. The results of this study further indicate that a CGI professional development workshop can have an effect on teachers' instructional decisions. Previously, researchers found positive results from such workshops related to addition and subtraction [1-6]. This study illustrates that a CGI professional development workshop on proportional reasoning can also lead to some positive changes in teachers' instruction to become more cognitively guided.

There were three major factors influencing Julie's ability to use the knowledge gained in the workshop to inform her instructional decisions: knowledge, perceptions of her students, and testing coupled with the school administration's policies. First, it may have been more difficult for the teachers with weak content knowledge to develop the strong pedagogical content knowledge that was the goal. According to Ball, Lubienski, and Mewborn [59], merely possessing knowledge of students' strategies, distinctions between problem types, and the relationship between problem characteristics and students' strategies "does not always equip the teacher with flexibility needed to manage the complexity of practice." In fact, according to Cooney [60], allowing students to invent their own strategies is difficult for teachers, because it "invites the unpredictable." He said, "Teaching for problem solving is risky business, because it invites the unpredictable and raises the question as to how many perturbable events a typical teacher can accommodate without fear of losing control of the class." Additionally, the Julie's confidence seemed to be related to her content and pedagogical content knowledge. She admitted having low confidence in her 
abilities to plan effective lessons (i.e. to know what to include and how to explain it). It has been found that teachers with greater self-efficacy are more willing to change their instruction [61].

Second, Julie's perceptions of her students' abilities, motivation, or needs were found to have some impact on the teachers' instructional decisions. Julie thought that her students were "lazy in their minds" and needed highly structured lessons to keep them focused. While she changed to encourage more thinking from her students, hence to teach in a more cognitively guided fashion, she could have guided her instruction more on their students' thinking. In order to do so, it seems that her true beliefs (expressed through their actions) needed to be more aligned with the beliefs underlying CGI.

Third, Julie indicated the influence that state mandated testing had on her instructional decisions. This is also consistent with many researchers' findings:

Today throughout the country, a major factor influencing what teachers teach is the student-testing program within the state, further complicated by the federal rulings regarding testing for Academic Yearly Progress (AYP) as mandated by the No Child Left Behind legislation and the threat of sanctions for schools that do not meet the required increases in scores. [52]

One implication from the findings of this study considered together with the existing body of literature is that teacher education programs, and professional development programs for inservice teachers, should focus on both content and pedagogical content knowledge, in addition to pedagogical knowledge. Without deep knowledge about specific content and strategies for teaching that content, teachers can feel lost when they are asked to teach it for the first time. Furthermore, teacher education programs should encourage teaching that is student-centered by modeling that type of instruction. I also think that professors should share their rationales for their instructional decisions, to model the decision making process.

Another implication is that practicing teachers are often lacking the tools (e.g. abilities to predict the strategies students will invent and to make sense of students' methods) necessary to allow their students to invent their own strategies. Professional development opportunities related to specific content areas need to be offered on a continuous basis. And through focusing on students' thinking in a professional development program, teachers can also increase their content and pedagogical content knowledge.

Finally, in 2010 in the United States $28.4 \%$ of public secondary mathematics teachers did not complete a major in mathematics and $12 \%$ had neither a major nor certification in mathematics [62]. Although the results presented in the case study are not generalizable, it is reasonable to believe that other individuals teaching outside of their original field of study would benefit similarly from content-based professional development.

Table 2. Comparison of the Characteristics of Teachers at Levels 1, 3, and 4A with Characteristics of Julie Before and After the Workshop.

\begin{tabular}{|c|c|}
\hline \multicolumn{2}{|r|}{ Characteristics } \\
\hline $\begin{array}{l}\text { A teacher at Level } 1 \text { does not: } \\
\text { believe students can develop problem solving } \\
\text { strategies on their own } \\
\text { use problem solving in the classroom } \\
\text { ask students about their thinking } \\
\text { use student thinking to make instructional decisions }\end{array}$ & $\begin{array}{l}\text { Prior to the workshop, Julie did not: } \\
\text { believe that her students could develop their own problem solving } \\
\text { strategies. She seemed to think that following procedures and mimicking } \\
\text { textbook examples was all that her students could handle. } \\
\text { ask her students to solve problems. She asked them to complete exercises } \\
\text { only. } \\
\text { ask her students about their thinking. Her questions all required } \\
\text { low-levels of cognitive demand. } \\
\text { Use student thinking to make instructional decisions, instead she relied on } \\
\text { the textbook materials for all of her decisions. }\end{array}$ \\
\hline $\begin{array}{l}\text { A teacher at Level 3: } \\
\text { allows students to solve problems in their own way } \\
\text { believes that students own solution methods make } \\
\text { more sense to them } \\
\text { uses a variety of problems } \\
\text { has students discuss their thinking }\end{array}$ & $\begin{array}{c}\text { After the workshop, Julie: } \\
\text { allowed her students to solve problems in their own ways } \\
\text { believed that there were many different approaches to solving problems } \\
\text { and let her students know that different ways are acceptable } \\
\text { used a variety of problems and ordered them to create a progression based } \\
\text { on the strategies they were likely to elicit from students or on their } \\
\text { difficulty } \\
\text { asked questions with high-levels of cognitive demand and expected her } \\
\text { students to share their thinking with the class }\end{array}$ \\
\hline $\begin{array}{c}\text { A teacher at Level 4A: } \\
\text { believes that students' thinking should drive } \\
\text { instructional decisions } \\
\text { problem solving is a major aspect of the classroom } \\
\text { activity } \\
\text { encourages students to share their thinking } \\
\text { describes in detail, individual student's thinking } \\
\text { makes instructional decisions based on students' } \\
\text { thinking }\end{array}$ & $\begin{array}{c}\text { After the workshop, Julie: } \\
\text { focused her lessons around problem solving } \\
\text { encouraged her students to share their thinking by asking them to share } \\
\text { how they solved different problems at the board and by asking questions } \\
\text { with high-levels of cognitive demand (e.g. "Why?" questions) } \\
\text { described some of her students' thinking in detail } \\
\text { based her instructional decisions while planning on her students' thinking } \\
\text { and described at least one instance when her instructional decision during } \\
\text { class was based on her students' thinking }\end{array}$ \\
\hline
\end{tabular}




\section{REFERENCES}

[1] T. P. Carpenter, E. Fennema, P. L. Peterson, C. Chiang, and M. Loef, "Using knowledge of children's mathematical thinking in classroom teaching," American Educational Research Journal, Vol. 19, 499-531, 1989.

[2] E. Fennema, T. P. Carpenter, M. Franke, L. Levi, V. R. Jacobs, and S. B. Empson, "A longitudinal study of learning to use children's thinking in mathematics instruction," Journal for Research in Mathematics Education, Vol. 27, No. 4, 403-434, 1996.

[3] M. Franke, T. P. Carpenter, E. Fennema, E. Ansell, and J. Behrend, J., 'Understanding teachers' self-staining generative change in the context of professional development," Teaching and Teacher Education, Vol. 14, No. 1, 67-80, 1998.

[4] M. Franke, T. P. Carpenter, L. Levi, and E. Fennema, "Capturing teachers' generative change: A follow-up study of professional development in mathematics," American Educational Research Journal, Vol. 38, No.3, 653-689, 2001.

[5] M. Franke, E. Fennema, and T. P. Carpenter, "Changing teachers: Interactions between beliefs and classroom practice," In E. Fennema \& B. Nelson (Eds.), Mathematics in Transition. Mahwah, New Jersey: Lawrence Erlbaum Associates, 1997, 255-282.

[6] P. L. Peterson, E. Fennema, T. P. Carpenter, and M. Loef, "Teachers' pedagogical content beliefs in mathematics," Cognition and Instruction, Vol. 6, 1-40, 1989.

[7] E. Hines, and M. T. McMahon, "Interpreting middle school students' proportional reasoning strategies: Observations from preservice teachers," School Science and Mathematics, Vol. 105, No. 2, 88-105, 2005.

[8] W. Ruchti, "Middle school students' use of pictorial models and discourse in the development and assessment of proportional reasoning," (Doctoral Dissertation, University of Idaho, 2005). Digital Dissertations, 137, 2005.

[9] R. Karplus, H. Adi, and A. E. Lawson, "Intellectual development beyond elementary school VIII: Proportional, probabilistic, and correlational reasoning," School Science and Mathematics, Vol. 80, No. 8, 673-683, 1980.

[10] R. Karplus, S. Pulos, and E. K. Stage, "Proportional reasoning of early adolescence," In R. Lesh \& M. Landau (Eds.), Acquisition of mathematics concepts and processes (pp. 45-90). New York: Academic Press, 1983.

[11] E. A. Lunzer, and P. D., "Understanding proportionality," Mathematics Teaching, Vol. 34, 7-12, 1966.

[12] C. Misailidou, and J. Williams, "Diagnostic assessment of children's proportional reasoning," Journal of Mathematical Behavior, Vol. 22, 335-368, 2003.

[13] G. Vergnaud, "Multiplicative structures," In R. Lesh \& M. Landau (Eds.), Acquisition of mathematics concepts and processes. New York: Academic Press, 127-174, 1983.

[14] W. Wollman, and R. Karplus, "Intellectual development beyond elementary school: Using ratio in differing tasks," School Science and Mathematics, Vol. 74, 593-613, 1974.

[15] G. Bright, A. H. Bowman, and N. N. Vacc, Teachers' frameworks for understanding children's thinking. Proceedings of Annual Meeting of the American Educational Research Association, 105-112, 1998.

[16] N. F. Knapp, and P. L. Peterson, "Teachers' interpretations of "CGI" after four years: Meaning and practices," Journal for Research in Mathematics Education, Vol. 26, No.1, 40-65, 1995.

[17] Author., (2008).

[18] S. J. Lamon, "Rational numbers and proportional reasoning: A theoretical framework for research," In F. Lester (Ed.), Second handbook of research on mathematics teaching and learning. Reston, VA: NCTM, 629-666, 2007.

[19] F. Tourniaire, and S. Pulos, "Proportional reasoning: A review of the literature," Educational Studies in Mathematics, Vol. 16, 181-204, 1985.

[20] P. Singh, "Understanding the concepts of proportion and ratio among grade nine students in Malaysia," International Journal of Mathematical Education in Science and Technology, Vol. 31, No. 4, 579-599, 2000.

[21] N. Bezuk, "Variables affecting seventh grade students' performance and solution strategies on proportional reasoning word problems" (Doctoral Dissertation, University of Minnesota, 1986). Digital Dissertations, 321, 1986.

[22] N. Bezuk, Effects of the numeric ratio on strategies used by preservice and inservice elementary teachers on proportional reasoning word problems. Proceedings of the 10th Annual Meeting of the North American Chapter of the International Group for the Psychology of Mathematics Education, 72-78, 1988.

[23] S. J. Lamon, "Ratio and proportion: Connecting content and children's thinking," Journal for Research in Mathematics Education, Vol. 24, No. 1, 41-61, 1993.

[24] R, Lesh, T. R. Post, and M. Behr, "Proportional reasoning.," In J. Hiebert \& M. Behr (Eds.), Number concepts and operations in the middle grades 2nd ed. Reston, VA: NCTM, 93-118, 1988.

[25] G. Vergnaud, "Multiplicative structures," In J. Hiebert \& M. Behr (Eds.), Number concepts and operations in the middle grades. Reston, VA: NCTM, 141-161, 1988.

[26] G. Vergnaud, "Multiplicative conceptual field," In G. Harel \& J. Confrey (Eds.), The development of multiplicative reasoning in the learning of mathematics. Albany, NY: State University of New York Press, 41-59, 1994.

[27] J. Piaget, J.B. Grize, A. Szeminska, and V. Bang, Epistemology and Psychology of Functions. Dordrecht-Holland/Boston-USA: D. Reidel Publishing Company, 1968/1977.

[28] R. Karplus, and R. W. Peterson, "Intellectual development beyond elementary school II: Ratio, a survey," School Science and Mathematics, Vol. 70, No.9, 813-820, 1970.

[29] S. J. Lamon, "Ratio and proportion: Children's cognitive and metacognitive processes," In T. P. Carpenter, E. Fennema, \& T. A. Romberg (Eds.), Rational numbers: An integration of 
research. Hillsdale, NJ: Lawrence Erlbaum Associates, 131-156, 1993.

[30] G. Noelting, "Development of proportional reasoning and the ratio concept: Part II- problem structure at successive stages: Problem-solving strategies and the mechanism of adaptive restructuring," Educational Studies in Mathematics, Vol. 11, 331-363, 1980.

[31] S. Chapin, and N. Anderson, "Crossing the bridge to formal proportional reasoning," Mathematics Teaching in the Middle School, Vol. 8, No.8, 420-425, 2003.

[32] K. A. Cramer, T. R. Post, and S. Currier, "Learning and teaching ratio and proportion: Research implications," In D. Owens (Ed.), Research ideas for the classroom, New York: MacMillen 159-179, 1993.

[33] S. J. Lamon, "Ratio and proportion: Cognitive foundations in unitizing and norming," In G. Harel \& J. Confrey (Eds.), The development of multiplicative reasoning in the learning of mathematics. Albany, NY: State University of New York Press, 89-120, 1994.

[34] M. G. Mila, E. Marti, C. Gomez-Granell, and B. Steren, Learning proportion using a computer environment in the classroom. Proceedings of the 20th Annual Conference of the International Group for the Psychology of Mathematics Education, 393-400, 1996.

[35] M. J. Fleener, S. L. Westbrook, and L. N. Rogers, Integrating mathematics with ninth grade physical science: The proportionality link. Paper presented at the Annual Meeting of the American Educational Research Association, Atlanta, GA, 1993.

[36] P. Heller, A. Ahlgren, T. Post, M. Behr and R. Lesh, "Proportional reasoning: The effect of two context variables, rate type and problem setting," Journal for Research in Science Teaching, Vol. 26, No.1, 205-220, 1989.

[37] P. Heller, T. Post, M. Behr, and R. Lesh, "Qualitative and numerical reasoning about fractions and rates by seventh and eighth grade students," Journal for Research in Mathematics Education, Vol. 21, No.5, 388-402, 1990.

[38] J. J. Kaput, and M. M.West, "Missing-value proportional reasoning problems: Factors affecting informal reasoning patterns," In G. Harel \& J. Confrey (Eds.), The development of multiplicative reasoning in the learning of mathematics. Albany, NY: State University of New York Press, 235-287, 1994.

[39] E. F. Karplus, R. Karplus, and W. Wollman, "Intellectual development beyond elementary school IV: Ratio, the influence of cognitive style." School Science and Mathematics, Vol. 74, No.6, 476-482, 1974.

[40] R. Karplus, E. F. Karplus, M. Formisano, and A. C. Paulsen, "Proportional reasoning in the people's republic of China: A pilot study," In J. Lockhead \& J. Clements (Eds.), Cognitive process instruction. Philadelphia: Franklin Institute Press, 105-107, 1979.

[41] R. Karplus, S. Pulos, and E. K. Stage, "Early adolescents' proportional reasoning on 'rate' problems," Educational Studies in Mathematics, Vol. 14, 219-233, 1983.

[42] R. Lesh, M. Behr, and T. Post, "Rational number relations and proportions." In C. Janiver (Ed.), Problems of representations in the teaching and learning of mathematics. Hillsdale, NJ: Lawrence Erlbaum, 41-58, 1987.

[43] J. Lo, and T. Watanabe, "Developing ratio and proportion schemes: A story of a fifth grader." Journal for Research in Mathematics Education, Vol. 28, No.2, 216-236, 1997.

[44] J. L. Miller, and J. T. Fey, "Proportional reasoning," Mathematics Teaching in the Middle School, Vol. 5, No.5, $310-313,2000$

[45] S. Pulos, R. Karplus, and E. L. Stage, "Generality of proportional reasoning in early adolescence: Content effects and individual differences," Journal of Early Adolescence, Vol. 1, No.3, 257-264, 1981.

[46] S. L. Weinberg, "Proportional reasoning: One problem, many solutions," In B. Litwiller \& G. Bright (Eds.), Making sense of fractions, ratios, and proportions. Reston, VA: NCTM, 138-144, 2002

[47] G. B. Saxe, M. Gearhart, and N. S. Nasir, "Enhancing student understanding of mathematics: A study of three contrasting approaches to professional support," Journal of Mathematics Teacher Education, Vol. 4, 59-79, 2001.

[48] G. B. Saxe, M. Gearhart, and M. Seltzer, "Relations between classroom practices and student learning in the domain of fractions," Cognition and Instruction, Vol. 17, 1-24, 1999.

[49] B. Inhelder, and J. Piaget, The growth of logical thinking from childhood to adolescence. New York: Basic Books, 1958.

[50] J. Piaget, and B. Inhelder, The psychology of the child. New York: Basic Books, Inc, 1969.

[51] G. Noelting, "The development of proportional reasoning and the ratio concept: Problem structure at successive stages: Problem-solving strategies and the mechanism of adaptive structuring," Educational Studies in Mathematics, Vol. 11, 331-363, 1980 .

[52] J. T. Sowder, "The mathematical education and development of teachers," In F. Lester (Ed.), Second handbook of research on mathematics teaching and learning. Reston, VA: NCTM,157-223, 2007.

[53] D. F. Steele, "The interfacing of preservice and inservice experiences of reform-based teaching: A longitudinal study," Journal of Mathematics Teacher Education, Vol. 4, 139-172, 2001.

[54] I. R. Weiss, J. D. Pasley, P. S. Smith, E. R. Banilower, and D. J. Heck, Looking inside the classroom: A study of $\mathrm{K}-12$ mathematics and science education in the United States. Chapel Hill, NC: Horizon Research, 2003.

[55] S. Kvale, Interviews: An introduction to qualitative research interviewing. Thousand Oaks, CA: Sage Publications, 1996.

[56] M. B. Miles, and A. M. Huberman, Qualitative data analysis: An expanded sourcebook (2nd ed.). London: Sage Publications, 1994.

[57] M. K. Stein, M. S. Smith, M. A. Henningsen, and E. A. Silver, Implementing standards-based mathematics instruction: A casebook for professional development. New York: Teachers College Press, 2000.

[58] M. S. Smith, E. A. Silver, M. K. Stein, M. Boston, M. A. Henningsen, and A. Hillen, Improving instruction in rational 
numbers and proportionality: Using cases to transform mathematics teaching and learning. New York, NY: Teachers College Press, 2005.

[59] D. L. Ball, S. T. Lubienski, and D. S. Mewborn, "Research on teaching mathematics: The unsolved problem of teachers' mathematical knowledge," In V. Richardson (Ed.), Handbook of research on teaching (4th ed.). Washington, DC: AERA, 2001.
[60] T. J. Cooney, "Conceptualizing teachers' ways of knowing," Educational Studies in Mathematics, Vol. 38, No.1, 163-187, 1999.

[61] P. Ashton, "Teacher efficacy: A motivational paradigm for effective teacher education," Journal of Teacher Education, Vol. 35, No.5, 28-32, 1984.

[62] S. Aud, M. Fox, and A. Kewal-Ramani, "Status and Trends in the Education of Racial and Ethnic Groups," p.49, 2010. 